Conference Paper

\title{
Analysis of reducing electrical losses in parallel transmission/distribution transformers
}

Firmin, J. and Vagapov, Y.

This is a paper presented at the2021 IEEE Young Researchers in Electrical and Electronic Engineering Conference, Moscow, Russia, 26-29 Jan 2021.

Copyright of the author(s). Reproduced here with their permission and the permission of the conference organisers.

\section{Recommended citation:}

Firmin, J. and Vagapov, Y. (2021), 'Analysis of reducing electrical losses in parallel transmission/distribution transformers.' In: Proc. 2021 IEEE Young Researchers in Electrical and Electronic Engineering Conference, Moscow, Russia, 26-29 Jan 2021, pp. 2645-2649. doi: 10.1109/EIConRus51938.2021.9396134 


\title{
Analysis of Reducing Electrical Losses in Parallel Transmission/Distribution Transformers
}

\author{
Joshua Firmin, Yuriy Vagapov \\ Faculty of Art, Science and Technology \\ Wrexham Glyndwr University \\ Wrexham, UK
}

\begin{abstract}
In 2014 then revised in 2019 the European Commission published regulations on the minimum specifications of new Eco Power Transformers. These regulations also required that transformers not meeting these requirements could no longer be installed or sold except under defined exceptions. Typically, almost all networks above $11 \mathrm{kV}$ operate with a parallel plant; especially when it comes to transformers. Using models of some transmission/distribution sites and by inputting twelve months of half-hour transformer loading data into these models; the amount of unnecessary losses, due to their parallel orientation, should be quantifiable. Since these sites need to be capable of supporting a varying load profile, they are for considerable periods of time oversized. Using the model, a sequence of taking offline excess plant will definable not only reducing network losses (a reduction in transformer losses of $35 \%$ per site is feasibly achieved in the model) but also marginally improve the sustainability of some of these existing sites.
\end{abstract}

Keywords-transformers; losses; sustainable capacity; parallel networks; auto voltage control

\section{INTRODUCTION}

After generators, power transformers are the backbone to the electrical industry allowing for practical generation voltages, long-distance transmission, and workable consumption; however, at every step-up or step-down in voltage power losses are accumulated [1]. The recent European Commission regulations [2], [3], whilst a step in the right direction, do little to address the losses in existing transformers.

Many sites above $11 \mathrm{kV}$ operate with parallel infrastructure [4]. This practice provides the practical consequence of allowing a plant to be taken out of service for maintenance and repairs without the inconvenience of interrupting the electrical supply to the consumer. For example, each of the transformers at a site with two transformers operating in parallel should be individually capable of meeting the total consumer demand of that substation. This means that, unless one transformer is out of service, in our two-transformer example, neither transformer should be loaded to more than $50 \%$ of its capacity.

Since these sites must be capable of meeting the maximum designed capacity demand at any time, it is conceivable that for a considerable amount of the time these sites are electrically underutilised and consequently accumulating losses that are disproportionate to their nominal loading trend. With the industry looking to operate and already developing a reactive or "smarter grid" [5], there is now the potential to control what plant is in service in reaction to the actual or predicted consumer loading.

The benefits of parallel infrastructure have long been discussed from automatic switching between transmission lines to maintain supply [4] to the economic and efficiency benefits [6]. In transmission, the primary interest of parallel networks is to improve the network "capacity, reliability and security" [7] or to share the capacity across several sites. It also means that a network can be constructed in several smaller, and thus cheaper, stages. Parallel networks also permit access to sections of the network for repair and maintenance without interrupting the supply. The only disadvantages commonly discussed are the effects parallel transformers have on fault levels and the difficulties in discriminating faults, particularly earth faults, between transformers. Again, transformer losses have long been discussed and are normally divided into load related losses and core related losses [1], [8]. These losses are further affected by electrical quality [9], [10].

The electrical modelling of non-linear transformers typically uses an ideal transformer in combination with several resistors and inductors arranged to affect the iron-losses, copper-losses and hysteresis [9], [11]. This technique, based on single-phase transformers, is so commonly accepted that it is found in Power Systems textbooks [12], [13] and as an example built into MATLAB's Simscape [14]. When it comes to three-phase transformers, it is common to simply duplicate the single-phase model. However, as three-phase, dual-winding transformers typically share a multi-limb core - more commonly using three limbs for economic reasons [11], [15] - there is an interaction between the magnetic phases [9], [16]. Again, MATLAB's Simscape holds an example of the magnetic circuit for both three and five limb three-phase transformers [17] This magnetic circuit forms the bases of Simulink's Simscape three-phase transformers. Consideration of transformer output voltage has also been neglected in many models, mainly because these models do not use and have not needed to use dynamic loads.

While there are plenty of simulations or models of parallel plant and transformer losses, there appears to be few looking at both together. In combining parallel transformer models with a view to investigating combined losses, it is clear that pure electrical modelling of the transformers will not be appropriate. Any model would need to observe both the electrical and the magnetic elements of the transformers. Any model would also need to ensure that the transformer output voltage retains acceptable stability [7]. 


\section{Methodology AND Assumptions}

The aim of this paper is to establish whether reducing the number of "inservice" transformers during times of reduced demand will reduce losses where there is parallel infrastructure. The research initially focuses on two main stages:

1. The development of a $33 / 11 \mathrm{kV}$ dual-circuit/dual-transformer substation model.

2. The simulation of load through the model in both a parallel and single path.

The model of a $33 / 11 \mathrm{kV}$ substation developed in MATLAB and Simulink incorporating several the electrical/Simscape toolboxes. The model partially simplifies typical designs of dual-circuit/dual-transformer $33 / 11 \mathrm{kV}$ substations to remove unnecessary complications to what will still be a sophisticated model. Also, since the reduction, monitoring and control of faults and fault current is not relevant to this research; all plant not directly required are also simplified or removed. These simplifications consist of but not limited to:

1. Combining the incoming $33 \mathrm{kV}$ circuits into a single supply source.

2. Combining the $11 \mathrm{kV}$ feeders into a single dynamic load.

3. Removing equipment that is not relevant to the model: (a) monitoring/metering transformers; (b) auxiliary transformers; (c) section breakers/isolators; (d) additional neutral/earthing plant.

\section{TRANSFORMER SPECIFICATION CONVERSION INTO PER-UNIT VALUES}

Before a computer model could be finalised; details of a $33 / 11 \mathrm{kV}$ transformer had to be acquired and converted into a format that could be implemented into the model.

The investigation is modelled on a Brush Dyn11 33/11kV 21MVA transformer with a rated HV (high voltage) current of $367.4 \mathrm{~A}$ and LV (low voltage) current of 1,102.2A. Because the certificate provided with the transformer does not contain pu values, these will need to be calculated prior to the insertion of these specifications into Simscape.

As a brief explanation Dyn 11 relates to the connection and phasor setup of the transformer windings. The upper-case ' $D$ ' indicates that the high voltage side of this transformer has a delta configuration whereby the windings are directly connected between the high voltage terminals. Each high voltage terminal is connected to two of the three windings. The lower-case ' $y$ ' signifies that the low voltage side of the transformer has a star configuration. The three low voltage windings are connected together at a common (neutral) point. The three low voltage terminals are each connected to one of the windings. With the ' $y$ ' is also a lower case ' $n$ ' which symbolises that there is a fourth accessible/available low voltage terminal for the neutral. It is important to note that with transformers Low Voltage side or windings do not necessarily mean that the voltage is considered as low voltage as defined by regulatory bodies; in the case of transformers, low voltage identifies the relation between the different voltages found at the terminals.
Finally, the ' 11 ' indicates the phase rotation between the HV and the LV terminals. Phase shifts from transformation are generally identified by numbers 0 to 11 [18]. 0 signifies no phase shift between $\mathrm{HV}$ and LV. With each additional interval, the phase vector shifts the by $30^{\circ} .11$ signifies a $330^{\circ}$ or $-30^{\circ}$ shift as shown in Fig. 1. This phase shift is not particularly relevant to this investigation other than to point out that transformers in parallel should have the same vector rotation. While parallel transformers may vary marginally in terms of impedance which will affect how the load is shared between the transformers and may introduce small amounts of circulating current between them; transformers with different vector shifts will cause high fault like currents to circulate between the transformers [19].

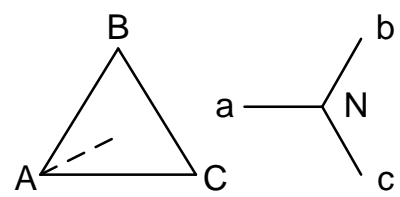

Fig. 1. Delta (D) and Star (y) windings and a $30^{\circ}$ vector rotation.

Per unit values of the transformer parameters referred to the base power of 21MVA are shown in Table I.

TABLE I. PU TRANSFORMER PARAMETERS

\begin{tabular}{|c|c|c|}
\hline Primary Winding & Secondary Winding & Magnetising Branch \\
\hline$R_{1}(\mathrm{pu})=0.0026 \mathrm{pu}$ & $R_{2}(\mathrm{pu})=0.0019 \mathrm{pu}$ & $R_{0}(\mathrm{pu})=3226 \mathrm{pu}$ \\
\hline$L_{1}(\mathrm{pu})=0.105 \mathrm{pu}$ & $L_{2}(\mathrm{pu})=0.105 \mathrm{pu}$ & $L_{0}(\mathrm{pu})=2548 \mathrm{pu}$ \\
\hline
\end{tabular}

\section{COMPUTER SimUlation MODEL}

The computer model is based on design documents and schematics of typical $33 / 11 \mathrm{kV}$ substations. When simplified as described will be similar to the sketch shown in Fig. 2. The transformers share a common source and a common load; one transformer will require a circuit breaker on both the primary and secondary sides providing total electrical separation as required. Having calculated the per-unit transformer values, these were incorporated into the Simscape model sown in Fig. 3.

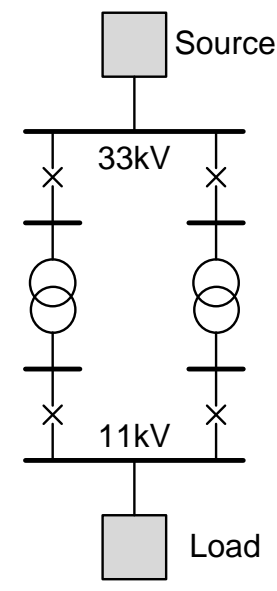

Fig. 2. Proposed model. 


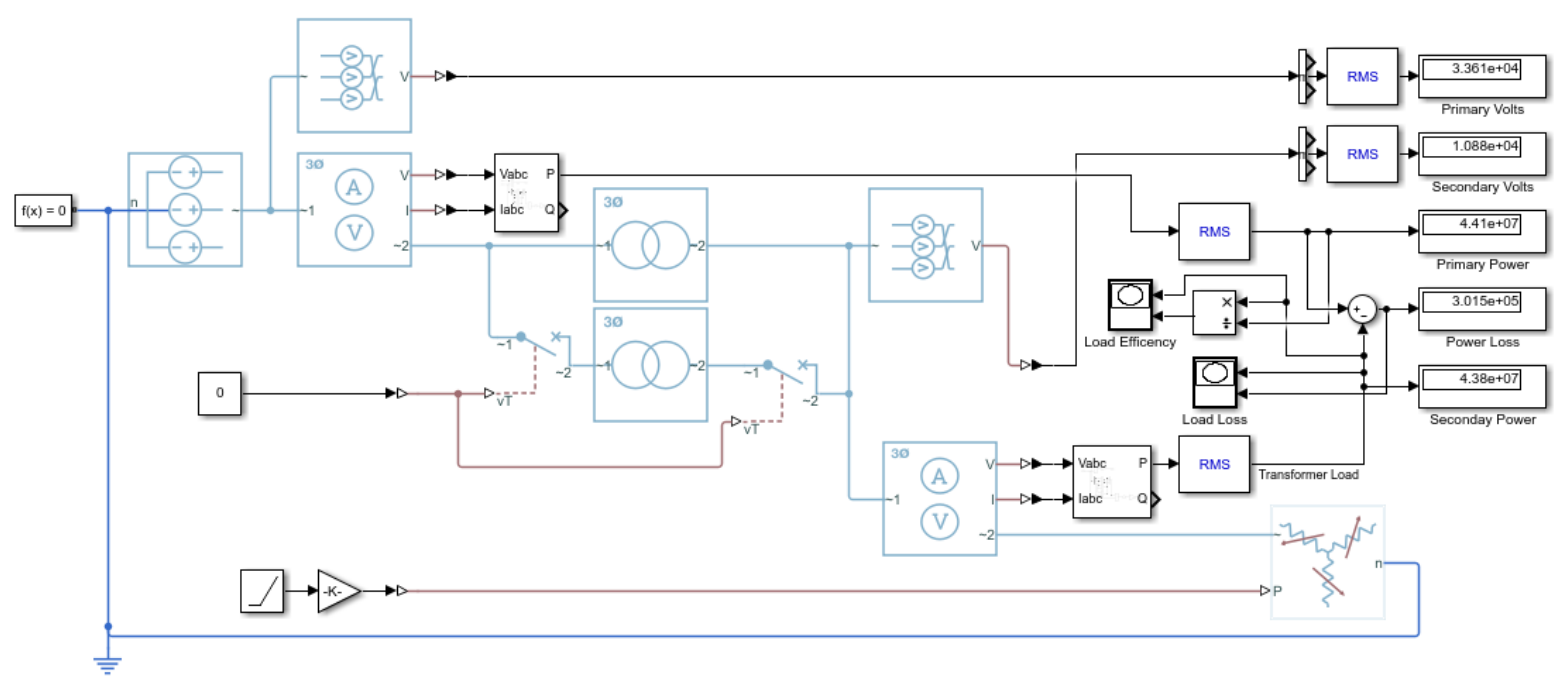

Fig. 3. Simscape Model.

The model incorporates a variable pure resistive star configured load as a power factor is not a consideration in this investigation. Because the load is also balanced, voltage readings are only collected from one phase with the RMS calculated by Simulink. The model is capable of disconnecting the second transformer simultaneously on both the primary and the secondary sides by the manipulation of the circuit breaker control value.

Power loss is also directly calculated by Simulink, to eliminate rounding errors that may arise if this were to be calculated later, by the following equation:

$$
P_{L}=P_{I N}-P_{\text {OUT }}
$$

where $P_{L}$ is power loss; $P_{I N}$ is input (primary) power; $P_{O U T}$ is output (secondary/load) power.

Efficiency shall be calculated as follows:

$$
\eta=\frac{P_{O U T}}{P_{I N}}
$$

Once the model is set to run in the parallel transformer setup a small amount of time settled after energisation, the load was steadily increased until the maximum rated load was reached. This process was repeated on a single transformer. Reading were collected every $200 \mathrm{kVA}$. The results are plotted on the graphs in Fig. 4 and Fig. 5.

These transformers are very efficient, exceeding $90 \%$ at only $1.8 \%$ of rated capacity and exceeding $99 \%$ efficiency above $22 \%$ of their rated capacity. Only above $93 \%$ of the rated capacity, approximately $19.5 \mathrm{MVA}$, does it become more efficient to operate both transformers together in parallel.

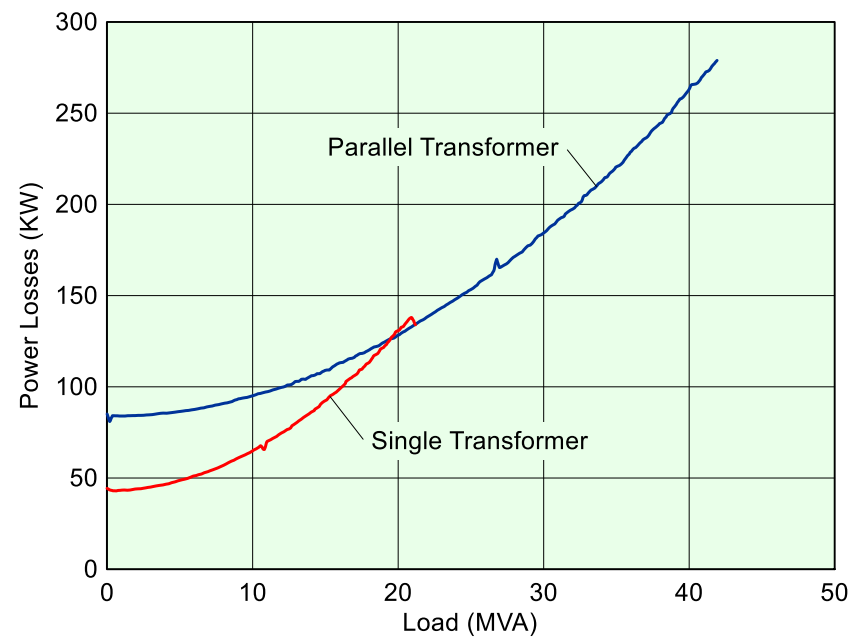

Fig. 4. Single and parallel transformer losses compared to load.

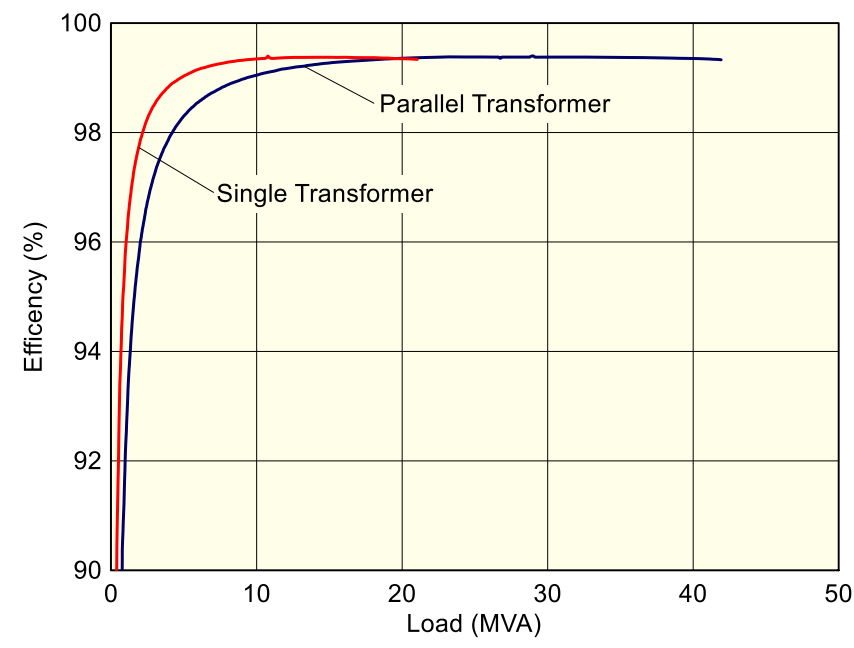

Fig. 5. Single and parallel transformer efficiencies compared to load. 


\section{SITE ANALYSIS}

Western Power Distribution provided the average half-hour readings for their sites in April 2018 [20]. Filtering only $33 / 11 \mathrm{kV}$ dual transformer sites that did not exceed 60MVA left a sample of 118 transformers at 59 substations. On the broad assumption that all of these transformers are 20MVA ONAN (Oil Natural Air Natural); transformers that exceeded $46.5 \%$ of this rating (half of the $93 \%$ maximum single transformer efficiency above) only one transformer exceeded this and only for $6 \mathrm{HH}$ (half-hourly) periods.

Based on this assumption, the remaining 58 substations could potentially have operated on a single transformer for the entire month. The modelled transformer had a no-load loss of $6,530 \mathrm{~W}$. Just in terms of no-load losses, the electrical saving of switching these 58 substations onto a single transformer is:

$$
P_{S}=N P_{N L} 24 T=58 \times 6.53 \times 24 \times 30=272,692.8 \mathrm{kWh}
$$

where $P_{S}$ is power savings; $N$ is the number of substation $N=58$; $P_{N L}$ is no-load power loss $P_{N L}=6.53 \mathrm{~kW} ; T$ is the number of days in April $2018 T=30.272 .69 \mathrm{MWh}$ at $£ 92.50 / \mathrm{MWh}$ [21] equates to $£ 25,223.83$ in potential savings for 58 substations in April 2018 or $£ 434.89$ per substation.

Looking deeper at one of these sites, total losses are analysed. Using the total $\mathrm{HH}$ loading of both transformers at Helston Substation and coordinating these with the single and parallel transformers from the models, the watt-hour savings could be calculated as such:

$$
W=0.5\left(P_{L P}-P_{L S}\right)
$$

where $W$ is watt-hour saving; 0.5 is half-hour; $P_{L P}$ is power loss (parallel transformers); $P_{L S}$ power loss (single transformer).

Combining both core and load losses Helston Substation could have potentially saved 23.259MWh of transformer losses by switching onto a single transformer which at $£ 92.50 / \mathrm{MWh}$ equates to $£ 2,151.46$ in potential savings in April 2018 .

TABLE II. TABLE OF SAVINGS

\begin{tabular}{|c|c|c|}
\hline & Savings in MW & Savings in GBP \\
\hline Core Loss Saving & $4.702 \mathrm{MW}$ & $£ 434.89$ \\
\hline Load Loss Saving & $18.557 \mathrm{MW}$ & $£ 1716.56$ \\
\hline Total Loss Saving & $23.259 \mathrm{MW}$ & $£ 2151.46$ \\
\hline
\end{tabular}

If the same savings could be averaged across the other 57 sites, the potential savings in April 2018 could have been $1.349 \mathrm{TWh}$ or approximately $£ 125 \mathrm{k}$. If these savings can be achieved for 6 months of the year, this equates to approximately 8.1TWh or $£ 0.75 \mathrm{M}$ in potential savings.

\section{ASSESSMENT OF THE RISKS}

One of the main risks with potentially disconnecting half of the transmission and higher distribution networks is that this would reduce network security. By having this infrastructure means that in the event of a fault, the network can, in some instances, remove the fault from the network without interrupting supplies. With this contingency removed there may potentially be several minutes required to restore supplies via the previously disconnected transformer where previously there may not have been an interruption. That said, one of the main issues with the parallel plant is that in the case of internal faults within a transformer or its connection; the fault can be supplied not only directly from the source but also from the secondary side of the parallel transformer. By reducing parallel plant, the fault levels on networks will reduce. This reduction in fault current should already be considered in the design of protection systems but will take on greater significance.

Careful consideration should also be given to sites where the load may suddenly increase. Although these transformers like the Brush one used in the model have available to them AFOF (air forced and oil forced) [22] cooling which increases a transformers capacity by as much as $50 \%$; this is not considered in the model, but it is likely that the efficiency of the transformer will reduce - especially considering that the fans and pumps will be consuming a fair amount of power. Although these additional cooling methods would reduce the risk of overloading a transformer whilst the parallel counterpart is brought online, there may be some sites where it would be prudent to bring these online earlier in anticipation of sharp increases in capacity.

Other considerations that will not be simply predictable solely from previous trends are the export variations form distributed sources like solar and wind. Both are prone to fluctuations that may suddenly increase or decrease demand on the transformers with power flowing in either direction.

\section{CONCLUSION}

From the model, it is clear that not insignificant electrical and monitory savings could be made by taking offline excess plant when it is not required, but further study would be required to establish whether it is feasible. If the application of the model accurately reflects savings that can be made across the 58 WPD (Western Power Distribution) sites and the implementation of automated controls is for example under $£ 10,000$ per site; the installation of this system could pay for itself in well under a year for many sites.

Every site would need to be assessed on an individual basis to ensure that the method of implementation does not drastically endanger the security of the supply, and those parallel transformers are brought online within reasonable lead time. Sites, where there are transformers of differing sizes, will undoubtedly need additional automation procedures. Any installation would also need to operate in cooperation with the AVC's (auto voltage control) to prevent dips or spikes in the supply voltage.

Moving forwards further investigation is required, and the next logical step would be to collect accurate, high sample rate, load data from a site and run this data through the model.

This investigation could also potentially extend to reducing losses in a distributed generation - reducing transformers in solar farms during low productive periods, or possibly in reducing transmission line capacitance - by taking offline transmission wires during times of low demand. 


\section{REFERENCES}

[1] J.C. Olivares-Galvan, P.S. Georgilakis, and R. Ocon-Valdez, "A review of transformer losses," Electric Power Components and Systems, vol. 37, no. 9, pp. 1046-1062, 2009, doi: 10.1080/15325000902918990

[2] Commission Regulation (EU) No 548/2014 of 21 May 2014 on implementing Directive 2009/125/EC of the European Parliament and of the Council with regard to small, medium and large power transformers, vol. 152, 2014.

[3] Commission Regulation (EU) 2019/1783 of 1 October 2019 amending Regulation (EU) No 548/2014 on implementing Directive 2009/125/EC of the European Parliament and of the Council with regard to small, medium and large power transformers (Text with EEA relevance), vol. 272, 2019.

[4] M. Kraiczy, T. Stetz and M. Braun, "Parallel operation of transformers with on load tap changer and photovoltaic systems with reactive power control," IEEE Transactions on Smart Grid, vol. 9, no. 6, pp. 6419-6428, Nov. 2018, doi: 10.1109/TSG.2017.2712633

[5] "Project Direction ref: WPD WMID." Western Power Distribution. https://www.westernpower.co.uk/downloads/2311 (accessed Aug. 25, 2020).

[6] J. Xiao, H. Li, and F. Luo, "Analysis of the increase of distribution network efficiency in parallel operation of the main transformers in highvoltage substations," in Proc. Int. Conf. on Sustainable Power Generation and Supply, Nanjing, China, 6-7 April 2009, pp. 1-4, doi: 10.1109/SUPERGEN.2009.5348304

[7] IEEE Guide for Paralleling Regulating Transformers, IEEE Standard C57153-2015, Apr. 2015, doi: 10.1109/IEEESTD.2015.7118615

[8] Z. Valkovic, "Calculation of the losses in three-phase transformer tanks," IEE Proceedings C - Generation, Transmission and Distribution, vol. 127, no. 1, pp. 20-25, Jan. 1980, doi: 10.1049/ip-c.1980.0004

[9] P. Picher, L. Bolduc, R. Gagnon, and G. Sybille, "Study of the apparent load loss unbalance in three-phase transformers," in Proc. Canadian Conf. on Electrical and Computer Engineering, Saskatoon, Canada, 1-4 May 2005, pp. 1473-1476, doi: 10.1109/CCECE.2005.1557258

[10] M. Digalovski, K. Najdenkoski, and G. Rafajlovski, "Impact of current high order harmonic to core losses of three-phase distribution transformer," in Proc. Eurocon 2013, Zagreb, Croatia, 1-4 July 2013, pp. 1531-1535, doi: 10.1109/EUROCON.2013.6625181
[11] M. Simic, T. Sekara, and S. Jokic, "Model of three-limb three-phase transformer based on nonlinear open circuit characteristic with experimental verification," Telfor Journal, vol. 6, no. 1, pp. 42-47, Jul. 2014, doi: 10.5937/telfor1401042S

[12] T.K. Nagsarkar, and M.S. Sukhija, Power System Analysis, 2nd ed. New Delhi: Oxford University Press, 2016.

[13] J.L. Kirtley, Electric Power Principles: Sources, Conversion, Distribution and Use, 2nd ed. Hoboken: Wiley, 2020.

[14] "Nonlinear transformer." MathWorks. https:/uk.mathworks.com/help/ physmod/sps/ref/nonlineartransformer.html (accessed Aug. 25, 2020).

[15] C.M. Arturi, "Transient simulation and analysis of a three-phase five-limb step up transformer following an out-of-phase synchronization," IEEE Transactions on Power Delivery, vol. 6, no. 1, pp. 196-207, Jan. 1991, doi: $10.1109 / 61.103738$

[16] A. Theocharis, J. Milias-Argitis, and T. Zacharias, "A systematic method for the development of a three-phase transformer non-linear model," International Journal of Circuit Theory and Applications, vol. 38, no. 8, pp. $797-827$, oct. 2010 , doi: $10.1002 /$ cta.599

[17] “Two-winding transformer (three-phase)." MathWorks. https://uk.mathworks.com/help/physmod/sps/ref/twowindingtransformer threephase.html (accessed Aug. 25, 2020).

[18] P. Putta. "Vector groups of transformer." Electrical Engineering Materials. https://electengmaterials.com/vector-groups-oftransformer (accessed Aug. 25, 2020).

[19] J. Parmar. "Principles of transformers in parallel connection." Electrical Engineering Portal. https://electrical-engineering-portal.com/principlesof-transformers-in-parallel-connection-1 (accessed Aug. 25, 2020).

[20] “WPD-April-2018-Analogue-Averages." Western Power Distribution. https://www.westernpower.co.uk

[21] "Hinkley Point C." GOV.UK. https://www.gov.uk/government/ collections/hinkley-point-c (accessed Jul. 20, 2020).

[22] EDS 08-1112 Substation LVAC Supplies, Engineering Design Standard, UK Power Networks, 2017. 